\title{
INSTITUTIONAL ISSUES FOR THE BULGARIAN TOURISM INDUSTRY FOLLOWING AMENDMENTS IN TAX LEGISLATION
}

\author{
M. Georgiev*, Iv. Dimitrova \\ Economics Department, Agricultural University, Plovdiv, Bulgaria
}

\begin{abstract}
The current study examines the institutional issues in the tourism sector of Bulgaria in terms of the impact of the by-law Ordinance № 18 of 13 December 2006 on the registration and reporting of sales in retail outlets through fiscal devices. The research applies: (1) defining the legal "error"; (2) the information asymmetries that pose a problem to the coordination mechanisms of the organization are described; (3) the negative economic effects are presented through the measurement of transaction costs. In conclusion, proposals have been made to improve this section of the institutional environment.
\end{abstract}

Key words: institutional impact, information asymmetries, governance structure, transaction costs

\section{INTRODUCTION}

The current study follows The New Institutional Economy (NIE) conception, implementing combined analysis, which spreads in fields of law, economy and organisation.

Ordinance № 18 (O-18) is a Bulgarian regulation, a source of Law, which regulates public fiscal issues. Some motives for implementing it are as follows: observing financial principles of accounting and transparency; setting of ERP format, which directly impairs the course and duration of addressees. The issuing institution O-18 assumes that the presented amendment refers to carrying the transaction cost into ex-ante of the process, which is expected to effect the reduction of the total expenditure of the economic agents.

The current study focuses upon the institutional impact of $\mathrm{O}-18$ on the tourist sector. The analysis is based on a sample of 100 companies involved in tour operating business. The selection of respondents is random, and it is not representative.

The information asymmetries, occurring under this behavioral model are established in the

\footnotetext{
*Correspondence to: Associate Professor Minko Georgiev*, PhD, Economics Department, Agricultural University, Plovdiv, Bulgaria, mm72gg@gbg.bg
}

article. The problems of some economic subjects and organisations are correlated with costs for readapting. The level of transaction costs allows an evaluation of the institutional environment to be made.

Therefore, the institutional impact and transaction costs in Bulgaria tour operator sector are being analyzed as:

a) A non-compliance of O-18 with the principles of legality and law - a prerequisite for obstacles (barriers) for the subjects;

b) Problems in the governance structure information asymmetries and their quasieffects over the expenditure of the economic agents and organisations;

c) Transaction costs as a database for estimating social costs;

d) An evaluation of the institutional impact O-18

The subject of the current study is touroperating business.

\section{ANAL YTICAL FRAMEWORK}

The institutional impact can be identified through legislation, in particular - through legal errors. Organization matters, because of the way the barriers, according the information asymmetry, define the coordination effects. Economy makes a difference for the set of instruments, used for economy assessment, 
hence the institutional impact. Economy is considered in connection of transactional costs. Law realism is a "segment" in theory of Law, outlining a critical approach towards the nature of the rules. $(9,5)$. On the other hand, a positive law analysis permits an interpretation of law in order to constitute a certain institutional unlawfulness.

The legal principle brings together the institutional impact and objectively defines a common direction. The effect is subjectively infiltrated:

(a.) directly in the conduct (and its deformations) of the issuer of the act and the addressee of the act;

(b.) indirectly for the rest of the subjects of economy system;

(c.) through their evaluation of the legal act, which prejudges their reaction- ergo whether they will conduct legally or they will deviate from the institutionally required conduct;

(d.) a new gradually established institution addressers and the rest consider demonstrating a certain conduct, e.g. they assume the institution acts differently - this way they constitute it.

If these general principles of Law have been infringed, it creates conditions for existence of informal institutions. In the current particular study framework, formal and informal rules in the governance structure are equally accepted. $(1,10)$.

Barriers are not analyzed although the last exist and predefine agents' expenditures. The requirement for processing information is growing due to need of new knowledge and skills. Coordination effects are multilateral
GEORGIEV M., et al. and, in some sense, chaotic. This leads to cost increase, especially for addressers of such an institutional impact. They also endure longterm losses. (6-8)

Eventually, effects could be determined as pursuing the selection, but also, creating the choice of cost effect (3). Costs are to be measured- subjectively and objectively. On the other hand, that should be used for determining losses in long - term perspective- as a loss of profits.

Such measuring of transaction costs helps for studying the institutional alternatives in various levels: a) to what the adaptation of the economy subjects and organizations is; b) direct estimation of the effectiveness of a certain rule of conduct.

\section{METHODOLOGICAL APPROACH}

The aim of the analysis is to determine the accordance of O-18 with the principles of Law and unlawfulness of the legal act. A period within the organization to operate is set. Barriers in front of the integration of the economy subjects are recognized. Obstacles that hinder the flow of information are described. Some acts or omissions of the subjects are identified.

Market and non-market costs are measured. Loss of profits, according Thrilby, G. concept, is defined. (11-13). The burden of losses for different groups of subjects is determined.

Final economic conclusion should be made by a simulated analysis. Costs are determined by the increasing of the total amount of the costs in the economy system.

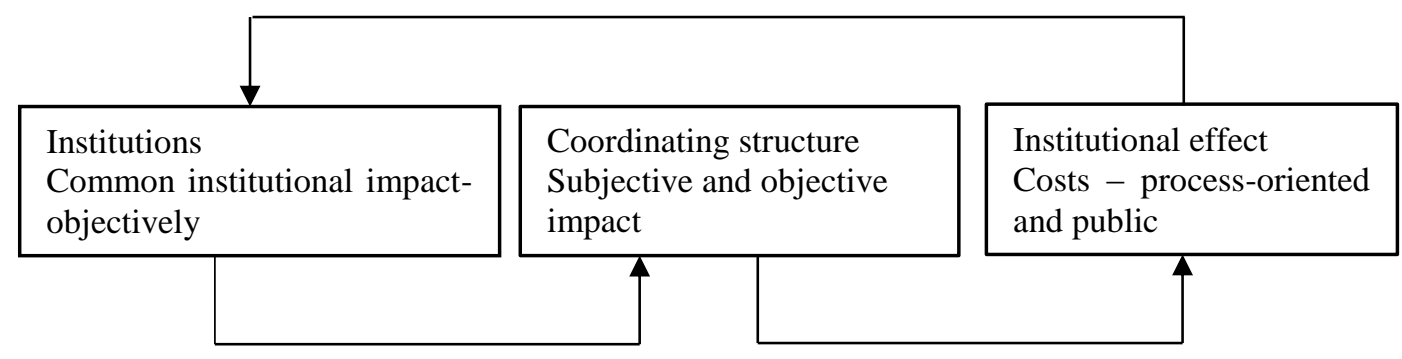

Figure 1. Methodological approach

Source: own concept

\section{A LEGAL ANALYSIS - IN THE CONTEXT OF (NIE)}

A possible contradiction of a certain legal act with a principle of the right should initiate an annulment of the act. Subjects, acting in good faith and according the Law, should not tolerate negative consequences after changes in any act. They are not to be affected by any 
transformations of the legal environment. In terms of any financial relationship, they have the right to claim a thorough and imperative formulation of the due, a result of its conduct, e.g. the act is to be apparent. The last means that, generally speaking, the legal act cannot lead to a negative result. Quasi- consequences are not expected to be undesired, ergo cost increase of the conduct, resulting in such an impact, also is considered as a discrepancy. Under these circumstances, the accordance of $\mathrm{O}-18$ with the principle of legal certainty and the legitimate expectations thereof should be questioned.

On the other hand, the neutrality principle is adopted in the fields of finance and tax law (14) Not intervening means that every legal act is to be consistent with the equal treatment for addressees. However, they undergo economic consequences as a result. That is to say, all must be equal not only before law, but also all consequences of the new legal environment must guarantee a long-term economic equal treatment. In the light of the incentives, which operate in various groups of subjects, a major difference can be recognized. It constitutes their different conduct, regarding investments in the market, where these groups operate. In fact, neutrality must be presented objectively, as well as subjectively. The current analysis reveals that some of the provisions in the legal act lead to a conduct as "a waiver of the right" for operating in the Bulgarian market, or "propensity to save" through unauthorized means. Such an impact of the legal act is considered unequal for all groups of subjects. We claim that O-18 does not fulfil the relevant neutrality criteria, regarding minor subjects.

In the reasoning, preceding the regulation has been alleged that it introduces standards for the EU right. This is not to say the analysis for the accordance with the right in the EU, considering (LW art. $28 \S 1$, i.5) of the Law of regulations (LR), is performed. The requirement is imperative, it goes along hand in hand with reference (LW art. 28), and the lack of the last invalidates the regulation.

There is an absence of analysis of the resources and the effect of the regulation implementation.

The last is a new ground of detection of contravenes in particular administrative production rules, taking into consideration (LW art. $28 \S 1$, i.4 and i.5) - ergo, again it is a defect since that regulation has been accepted.

\section{BARRIERS - INFORMATION ASYMMETRIES}

The idea of this regulation is to place business in a better and competitive environment, tourism included, by implementing an integrated system for organizations, regarding their fiscal liabilities. However, that regulation establishes coordination inadequacy to most of the addressees. There are certain barriers for the information asymmetry, which flows on the surface - an administrative authorityaddressee of the rule of conduct.

The institution impact determines:

Information flows in one direction only- thus, it presumes a lack of a feedback. An organization asymmetry can be established when addressees are not aware if particular operation has been reported- they repeat the accounting operation on paper.

Information without coordination between institutional and technical effect- the absence of paper- based form, does not submit clear evidence for the exchange of documents, which establishes uncertainty for the addressees - some of them will reinsure or decline the act.

Hardware changes (implementing the new technology) - they enable multi-dimensional new information flow and diminish adaptability of the subjects. Ultimately, this delays the flow itself.

Unclear texts provoke an opportunity for haphazard interpretation on behalf of both, business and the verifier- National Revenue Agency.

That leads to a growing need of:

- An initiative for obtaining new machines and software;

- Additional actions on the horizontal, negotiating new service, ensuring the devices.

- Additional actions on the vertical, considering the relationship of the addressees with the administrative authority.

- Actions, involving further education of people, who are to work in a new environment.

The institution O-18 provokes secondary problems, following the agents' will to avoid long-term risks. The last presumes that additional measurements are required. 


\section{AN INSTITUTIONAL EFFECT \\ MEASUREMENT}

In the current measurement, respondents are separated in groups. Small firms with 1 to 3 employees constitute $60 \%$. Only $6 \%$ constitute the biggest firms in the branch with over 20 employees. According European Travel Agents' and Tour Operators' Associations, in 2018 there were 4325 tour operators and tour agencies registered in Bulgaria.
GEORGIEV M., et al.

Figure 2 shows what the percentage of perspective additional expenses of firms in the tourist branch could be. With smaller firms, the costs will be higher and will reach approximately $25 \%$ of their activity turnover. With bigger firms, reasonably, these expenses are minor - approximately 7-8 \% of their activity turnover.

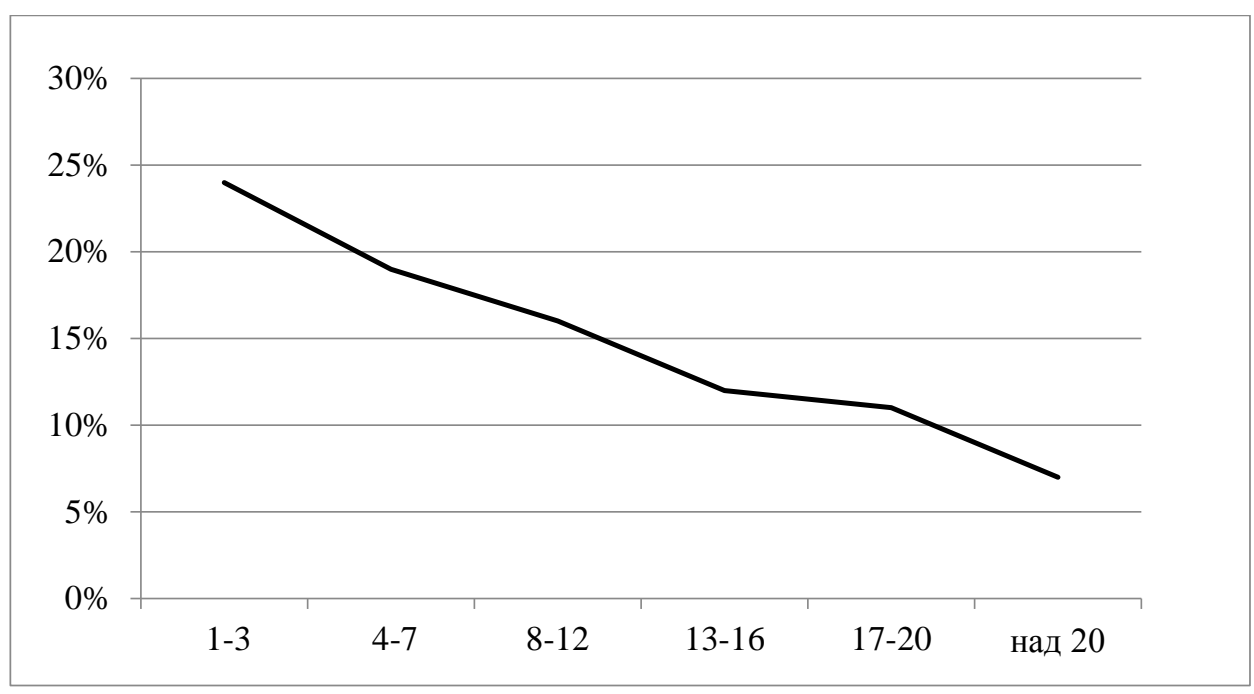

Figure 2. Costs, shown in percentage (according the size of the firms)

Source: own concept

In that context it can be concluded that additional public costs can be estimated to $48604207 \mathrm{lv}$ only for the first year. In the second year they will be reduced, but, still, for smaller firms these costs will constitute a significant share of their activity (5-6\%)

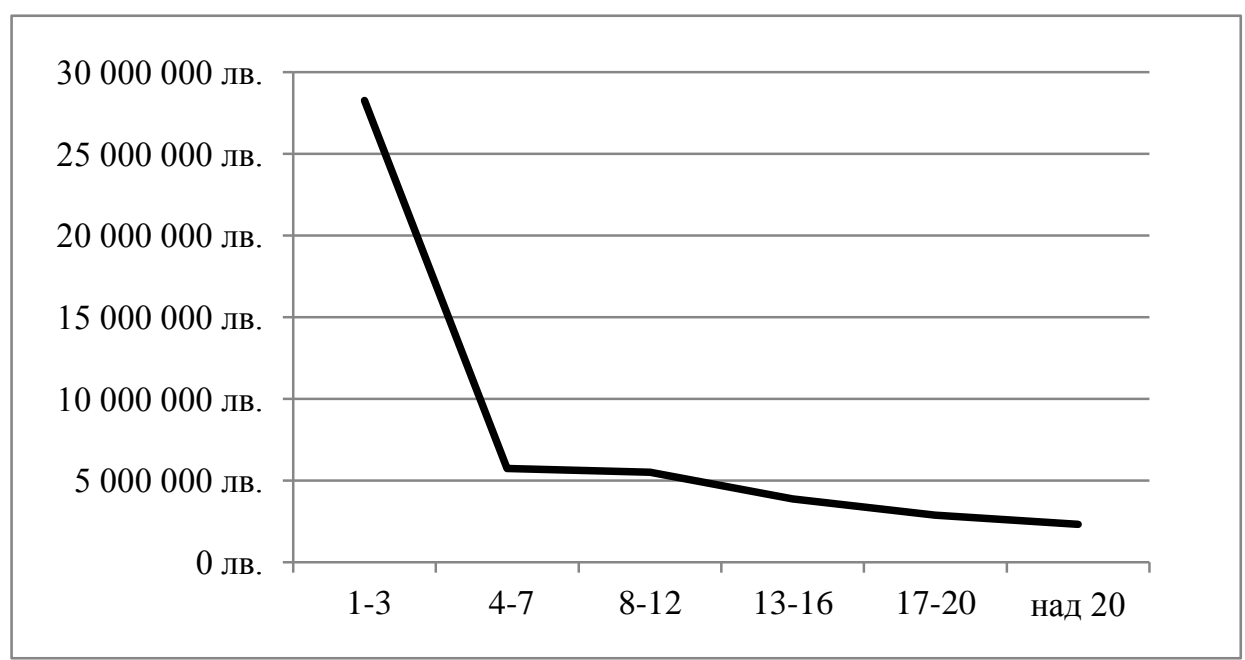

Sourse: own concept

Figure 3. Costs spend for a year, according the size of the firm

The last mentioned will establish a few of the secondary effects- strategies, aiming reduction of some long-term risks. A few firms will restructure their conduct by: a. Annulment of rights, remaining "a physical format"- this can be an indicator for a longterm downturns;

b. An exit from the market as cost-cutting measures, considering possible penalty, or a 
changeover to the informal sector of the economy;

c. Developing "claim on annuity" forms.

\section{CONCLUSION}

With the current study we claim that, firms in the studied branch will suffer only losses. These losses will reach the sum of 49 million lev. Also, if indirect costs are taken in consideration these losses can measure up to 130 million per year. These are expences for the entire society.

Possible expences for declaring invalidity of the Act must be added up, as well as unrealised capital gains due to exit of market (migration of firms). These expences should be compared to fiscal income. That means the istitution $\mathrm{O}$ 18 causes institutional problems in the tourist sector.

\section{Recommendations:}

An implementation of the regulation as a matter of urgency according both, the right in the EU and Bulgarian legislation- revision of texts inconsistent with the specific agents' and tour operators' business. Placing in service an integrated digital format of the services regarding O-18 at the expence of the act issuer, by which costs have not been transferred to smaller economic subjects.

\section{Guidelines for the continuation of the current} study:

Analysing the fact which economic agents will be benefiting, unjustified in such act of the institution O-18; what the new way of subordination in rules will be ; other effects of such interaction. The actual amount of "claim on annuity".

\section{REFERENCES:}

1. Baron, David P.; Myerson, Roger B. (1982). "Regulating a Monopolist with Unknown Costs". Econometrica. 50 (4): 911-930. CiteSeerX 10.1.1.407.6185. doi:10.2307/1912769. JSTOR 1912769

2. Benham A. and Lee Benham 2001 "The Costs of Exchange.". R Ronald Coase Institute Working Papers, Number 1.

3. Buchanan J. M. 1999 The Collected Works of volume 6 Cost and Choice An Inquiry in Economic Theory liberty fund Indianapolis,
GEORGIEV M., et al.

First published in 1969 by Markham Publishing Company, Chicago, Ill.

4. Coase, R. 1946 "The Marginal Cost Controversy," Economica, XIII, 169- 82.

5. Green, M. 2005 Legal Realism as Theory of Law. William \& Mary Law Review, Vol. 46,. pp. 1915-2000, Available at SSRN: https://ssrn.com/abstract=761007

6. Hoppe, Eva I. (2013). "Observability of information acquisition in agency models". Economics Letters. 119 (1): 104-107. doi:10.1016/j.econlet.2013.01.015. ISSN 0165-1765

7. Hoppe, Eva I.; Schmitz, Patrick W. (2010). "The costs and benefits of additional information in agency models with endogenous information structures". Economics Letters. 107 (1): 58-62. doi:10.1016/j.econlet.2009.12.026. ISSN 0165-1765.

8. Hoppe, Eva I.; Schmitz, Patrick W. (2013). "Contracting under Incomplete Information and Social Preferences: An Experimental Study". Review of Economic Studies. 80 (4): 1516-1544. doi:10.1093/restud/rdt010

9. Leiter, B 2002 American Legal Realism. U of Texas Law, Public Law Research Paper No. 42. Available at SSRN: https://ssrn.com/abstract=339562

10. Stiglitz, J. E. "Using Tax Policy to Curb Speculative Short-Term Trading," Journal of Financial Services Research, 3(2/3), December 1989, pp. 101-115. Reprinted in The Selected Works of Joseph E. Stiglitz, Volume II: Information and EconomicAnalysis: Applications to Capital, Labor, and Product Markets, Oxford: Oxford University Press, 2013, pp. 85-98

11.Thirlby, G. 1946, "The Ruler,' South African Journal of Economics, XIV, 25376.

12.Thirlby, G. 1946, "The Subjective Theory of Value and Accounting Cost," Economica, XIII, 32-49.

13.Thirlby, G. 1947 "The Marginal Cost Controversy: A Note on Mr. Coase's Model,' Economica, XIV, 48-53.

14.OECD (2014), "Fundamental principles of taxation", in Addressing the Tax Challenges of the Digital Economy, OECD Publishing, Paris. DOI: https://doi.org/10.1787/9789264218789-5en 